\title{
Identifying post stroke patients in the Malaysian community: Profile of patients managed at ten selected public health centres in Peninsular Malaysia
}

\author{
Aznida Firzah Abdul Aziz ${ }^{1 *}$, Noor Azah Abd Aziz², Saperi Sulong², Syed Mohamed Aljunid ${ }^{1}$ \\ From 7th Postgraduate Forum on Health Systems and Policies \\ Phitsanulok, Thailand. 24-25 June 2013
}

\section{Background}

Post stroke patients are managed either at hospital-based specialist outpatient or primary care clinics after acute stroke. There is scarce local data on patients receiving treatment at primary care after hospital discharge. This study aimed to determine the profile of post stroke patients managed at public health centres in Peninsular Malaysia.

\section{Materials and methods}

Practice registry lists at ten public health centres were screened for patients with cerebrovascular accident (CVA) between July and December 2012. Patients aged $\geq 18$ years with recorded diagnosis of CVA either radiographically or by referring physician were recruited. Patients with transient ischaemic attack, traumatic brain injury or isolated nerve palsies were excluded. Details of stroke risk factors and clinical findings at first primary care visit were extracted from case notes and from patient/and carer interviews. Data were analysed for mean, median and proportions.

\section{Results}

Total of 121 patients were recruited. Mean age at stroke was $56.3(\mathrm{SD} \pm 10.1)$ years, with $78.7 \%$ at $\leq 5$ years poststroke. Median duration between acute stroke and contact with primary care team was 160 (0-10564) days. Main cause of stroke was ischaemia (73\%) followed by haemorrhage $(8 \%)$. For stroke risk factors: $87.9 \%$ had

\footnotetext{
* Correspondence: aznidaf@yahoo.com

'UNU IIGH, Universiti Kebangsaan Malaysia, UKM Medical Centre Complex, Jalan Yaacob Latif, 56000 Cheras, Kuala Lumpur, Malaysia

Full list of author information is available at the end of the article
}

hypertension, $76.5 \%$ had type 2 diabetes mellitus, $85.3 \%$ dyslipidaemia and $8 \%$ were current smokers. Target blood pressure control achieved for diabetics $(\leq 130 / 80 \mathrm{mmHg})$ was $30.2 \%$ and non-diabetic patients $(\leq 140 / 90 \mathrm{mmHg})$ $47.8 \%$. Mean total cholesterol was 5.1 (SD \pm 1.1 ), LDLcholesterol 3.0 (SD \pm 0.9$)$, HDL-cholesterol 1.2 (SD \pm 0.3 ) and median triglyceride level $1.5(0.5-7.2) \mathrm{mmol} / \mathrm{L}$. It was found that $77.3 \%$ had undergone rehabilitation with median duration 5.3 (0.3-6) months for physiotherapy and 8.0 (3-6) months for occupational therapy. For functional status, $47.6 \%$ had moderate to total dependence.

\section{Conclusions}

Post stroke patients at primary care were younger than expected. Contact with primary care after discharge from hospital should be expedited to optimise treatment of risk factors, especially blood pressure control. Occupational therapy was the predominant type of rehabilitation utilised.

\section{Authors' details}

'UNU IIGH, Universiti Kebangsaan Malaysia, UKM Medical Centre Complex, Jalan Yaacob Latif, 56000 Cheras, Kuala Lumpur, Malaysia. ${ }^{2}$ Jabatan Kesihatan Masyarakat, Pusat Perubatan Universiti Kebangsaan Malaysia, Jalan Yaacob Latif, Bandar Tun Razak, 56000 Cheras, Kuala Lumpur, Malaysia.

Published: 29 January 2014

doi:10.1186/1471-2458-14-S1-P20

Cite this article as: Abdul Aziz et al:: Identifying post stroke patients in the Malaysian community: Profile of patients managed at ten selected public health centres in Peninsular Malaysia. BMC Public Health 2014 14(Suppl 1):P20. 